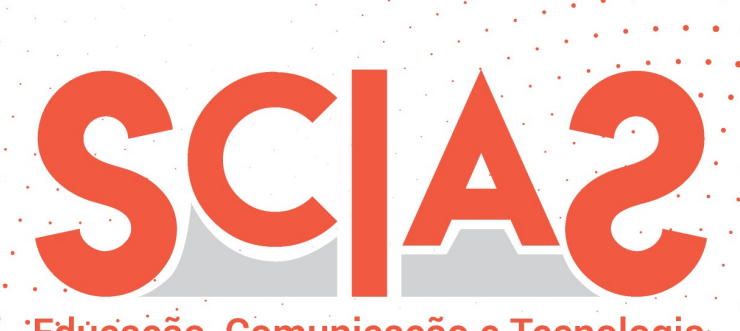

Eduçaçẳo, Comunicação e Tecnologia

Atribuição BB CY 4.0

\title{
Mulher, mãe e professora: desafios e ressignificações na prática docente e na pesquisa em tempos de ensino remoto
}

\author{
Maria Izaíra da Silva Gil ${ }^{1}$
}

\section{Resumo}

O seguinte artigo tem como objetivo relatar alguns dos desafios de ser mulher, mãe, professora e pesquisadora em tempos de ensino remoto em Manaus Amazonas. Para esse fim fez-se necessário estudo bibliográfico sobre a mulher na educação, buscando pontuar alguns aspectos latentes a feminização da profissão docente, sendo atualmente a mulher o grande público profissional da educação. Destaca-se os desafios com uso da tecnologia como ferramenta pedagógica para colaborar no processo de ensino-aprendizagem nas aulas remotas, a visão crítica sobre o projeto Aula em Casa, desenvolvido pelas secretarias de educação do estado do Amazonas e prefeitura de Manaus, que através de cooperação técnica transmitem aulas por canal televisivo e internet, acompanhado pelos professores através de uso de mídias sociais na visão da professora. E ainda, o desafio da pesquisadora que se coloca como mulher professora e pesquisadora em um mestrado em Ensino Tecnológico no cenário da pandemia COVID-19. Pontua-se a partir da percepção do relato a visão da autora sobre alguns desafios enfrentados, destacando ressignificações dentro dessa narrativa da mulher que é professora e pesquisadora no momento histórico de uma pandemia.

\section{Palavras-chave}

Mulher. Mãe. Professora. Pesquisadora. Ensino Remoto.

Recebido em: 31/07/2020

Aprovado em: 26/01/2021

\footnotetext{
${ }^{1}$ Sou Licenciada em Pedagogia e bacharela em Administradora Pública. Atuo como professora da SEMED - AM, e também, como professora tutora em uma Instituição de Ensino Superior privada. Sou mestranda em Ensino Tecnológico pelo Instituto Federal de Educação e Tecnologia do Amazonas, com áreas de interesse em formação de professores, histórias de vida, mulher, identidade docente feminina, coordenação pedagógica e políticas educacionais.

E-mail: m.izairagil@gmail.com
} 


\section{Female teacher: challenges and resignifications teaching practice and research in times remote teaching}

\section{Abstract}

The following article report challenges of being woman, mother, teacher and researcher in times of remote teaching in Manaus - Amazonas. The bibliographic study women in education was necessary, seeking highlight some clear aspects feminization the teaching profession, with women currently being professional public in education. We highlight challenges with use technology pedagogical tool to collaborate in the teaching-learning process remote classes, the critical view on the Aula em Casa project, developed by the education departments of the state of Amazonas and Manaus city hall, which through of technical cooperation transmit classes by television channel and internet, accompanied by teachers through use social media. And yet, challenge researcher who poses as a female teacher and researcher in a master's degree in Technological Education in scenario pandemic COVID-19. From perception report, the author's view of some of challenges faced is highlighted, highlighting resignifications within this narrative of the woman who is a teacher and researcher at the historic moment pandemic.

\section{Keywords}

Woman. Teacher. Researcher. Remote Teaching. 


\section{Introdução}

A pesquisa parte da inquietação e desejo de relatar a percepção e desafio da mulher que é mãe, professora e pesquisadora sobre as práticas educacionais desenvolvidas no estado do Amazonas dentro do cenário que envolve a pandemia COVID-19, e o avanço das aulas do ensino público no formato remoto, desafios e possibilidades.

Registra-se a evidência da tecnologia como grande aliada e colaboradora, retomando uma discussão sobre a o uso das tecnologias como ferramenta pedagógica, o que está marcado nos documentos: Lei de Diretrizes e Bases da Educação - LDB 9394/96, Base Nacional Comum Curricular - BNCC.

Para tanto, se utiliza o método de Estudos Culturais, por se tratar do campo específico da mulher, e do desafio que compõe a própria trama social dentro da educação básica, diante da pandemia e se trata de uma pesquisa qualitativa, em que se buscou narrar os desafios e percepções da autora/atora dentro da sua prática docente, e os desafios que se coloca como mulher, mãe, professora e mestranda, enfrentando a prática docente no desenvolvimento do ensino de forma remota, e os desafios na pesquisa.

A pandemia coloca em cheque as práticas desenvolvidas em modo presencial, por conta da necessidade do afastamento para evitar maior contaminação, e evidencia práticas com o uso das tecnologias, o que chega como uma alternativa possível para não ferir o desenvolvimento do ensino que foi interrompido bruscamente, a partir da ordem de fechamento das instituições públicas e privadas.

Após o anúncio do primeiro caso de COVID - 19 no Amazonas, o sentimento de medo toma conta da população, de uma forma mais latente após a publicação do Diário Oficial do Estado do Amazonas, em 16 de março de 2020, com Decreto $n^{\circ}$ 42.061, que: "Dispõe sobre a decretação de situação de emergência na saúde pública do Estado do Amazonas, em razão da disseminação do Coronavírus, e institui o Comitê Intersetorial de Enfrentamento e Combate ao 
COVID-19.". Composto por representantes das secretarias do estado, em especial a da Educação, Casa Civil, Superintendência de Navegação, Portos e Hidrovias, Agência Reguladora dos Serviços Públicos, com a incumbência de instituir as diretrizes para superar o momento de emergência na saúde do Amazonas. Diante deste cenário se coloca o desafio do ser mulher que é mãe, professora e pesquisadora retomando a problemática da feminização da educação e fazendo o paralelo com a descrição do relato de experiência da autora dentro deste processo.

\section{Desafios do ser mulher - uma breve visão histórica}

Historicamente a mulher se construiu como profissional da educação com as amarras do patriarcalismo, registrando em determinado tempo da história considerada como ser incapaz. Sendo afastada do desenvolvimento científico, e deveria ter a incumbência de cuidar da casa, dos filhos e do marido, saber se comportar na sociedade e não precisava ter estudos mais aprofundamos sobre determinado conhecimento científico, desconsiderando o estudo das disciplinas complexas, para se dedicar a disciplinas que fizessem ser melhor dentro do papel estipulado pela sociedade da época de mãe e esposa.

Segundo Almeida (1999, p.32), a mulher adentra o magistério, por ser este o equilíbrio aceitável e desejado dentro de sua especificidade:

Situa-se aí a extrema ambigüidade da posição feminina a respeito de trabalho e instrução, representada pelo equilíbrio entre a condição desejável e a possível de se obter. O magistério, por sua especificidade, foi uma das maiores oportunidades com a qual contou o sexo feminino para atingir esse equilíbrio. Era aceitável que as mulheres desempenhassem um trabalho, desde que este significasse cuidar de alguém.

Outra visão marca a presença da mulher na escola com o olhar do sacerdócio, a mulher como mãe tinha o papel no cuidado com os filhos, uma missão imaculada e por esse motivo iria cuidar melhor dos alunos, essa era sua missão, cuidar, um sacerdócio tão importante que deveria ser feito de forma voluntária, por amor, sem a necessidade de um salário.

Para Dametto e Esquinsani (2015, p.150): 
Para que a expansão escolar às custas da mão de obra feminina fosse palatável, houve um investimento em representações acerca da mulher e do magistério que conduziram a interpretações que persistem há muito tempo, como a ideia do magistério enquanto missão ou sacerdócio, além de ser uma vocação feminina natural.

Com o avanço social, processo de industrialização, necessidades de mercado, entre outros fatores colocam a mulher em evidência como mão de obra barata e necessária, desta forma ela começa a vencer esses estereótipos e adentra a escola, acompanhando historicamente um processo de feminização do magistério, porém a desvalorização da profissão, desprestígio social, luta salarial acompanham o processo, mas é um primeiro ganho diante da luta da mulher para conquistar seu espaço e reconhecimento como profissional. O que se discute a seguir dentro da trama que envolve o ensino em tempos de pandemia.

\section{O ensino e pandemia - caminhos e desafios da professora}

A Lei de Diretrizes e Bases da Educação - LDB 9394/96 prevê em casos emergenciais o uso de aulas à distância para colaborar no desenvolvimento do ensino, a Base Nacional Comum Curricular reafirma as competências e habilidades a serem desenvolvidos com uso das tecnologias na educação tanto de forma interdisciplinar como colaboradora no ensino para aproximar as práticas educacionais ao contexto dos alunos imersos na tecnologia, vindo de encontro à necessidade de uma formação integral.

Porém, com o período de pandemia o uso e domínio das tecnologias se tornam totalmente essenciais, pela necessidade de distanciamento, as aulas remotas são o caminho encontrado pelas instituições porque usam os instrumentos tecnológicos para ministrar aulas em tempo real, como se estivessem acontecendo em uma sala de aula, e as secretarias de educação estadual e municipal resolvem dar andamento as aulas de forma remota no estado do Amazonas.

A Resolução no 30/2020 Conselho Estadual de Educação/AM de 18.03.2020, no art. $2^{\circ}$, estabelece: 
Estabelecer regime de aula não presencial no âmbito de todo o Sistema de Ensino do estado do Amazonas, definindo essencialmente pela manutenção das atividades pedagógicas sem a presença de alunos ou professores nas dependências escolares, dependendo se efetivar por meio de regime de colaboração entre entes federados e autoridades do sistema de ensino do estado do Amazonas.

A secretaria estadual de educação por conta da grande diversidade que compõe o Amazonas, principalmente no que se trata a diversidade demográfica do estado, já possui um modelo de transmissão de aula que atende principalmente o interior do Amazonas com educação tecnológica, e esse modelo se expande

para atender as necessidades de isolamento impostas pela pandemia, com a paralisação das aulas presencias. A secretaria municipal de educação no primeiro momento inicia as atividades com o uso dos aplicativos de mensagem, uso de e-mail, aplicativos de vídeo e faz uma parceria com o estado para também participar do projeto desenvolvido.

De acordo com as Diretrizes Pedagógicas para o Regime Especial de Aulas Não Presenciais do Estado do Amazonas (2020, p.23), coloca-se;

Destaca-se que o Regime Especial de Aulas não Presenciais trata-se de um plano de ações estratégicas que requer o envolvimento dos atores educacionais e da comunidade escolar, a fim de que o mesmo seja implementado, cumprindo o objetivo de subsidiar o envolvimento de aprendizagens dos estudantes da rede pública estadual dos diversos níveis, etapas e modalidades da Educação Básica. Assim, a participação e a responsabilidade dos atores frente às atividades são condição primordial para o sucesso da proposta.

Desta forma, a secretaria busca mobilizar os professores e os demais atores educacionais para que o projeto tivesse sucesso em continuar o processo desenvolvimento de aprendizagens aos alunos iniciado em 2020, o que se estende a secretaria municipal de educação. As aulas começam a ser transmitidas através da televisão, sites e aplicativos e os professores acompanham esse processo através dos grupos de mensagens.

A pandemia tornar-se muito grave em Manaus, o número de mortos começa a subir rapidamente, e o desafio que até então era organizar o exercício da autonomia e produção diária na vida de mulher professora e mestranda, começa a se misturar com o drama dos primeiros contaminados e a perda de 
conhecidos, vítimas do vírus. Os papéis de mãe, mulher, docente, pesquisadora se entrelaçam com a dor e a necessidade de resiliência, educação emocional, necessidade de pesquisa, aprimoramento das habilidades tecnológicas, cuidar dos filhos, da casa, do próprio isolamento e das práticas que iniciaram com as aulas remotas.

Em $1^{\circ}$ de abril de 2020, iniciam as aulas com suporte televisivo e uso de canais na internet para atender a grande demanda de alunos da Secretaria Municipal de Educação - SEMED, após, acordo firmado de apoio técnico com a Secretaria de Estado da Educação e Qualidade de Ensino - SEDUC. Até então, estava fazendo vídeos orientando as atividades e solicitava o acompanhamento dos pais através do contato com uso de grupos feitos com ajuda do aplicativo de mensagens instantâneas, através do Projeto Aula em Casa.

A Resolução $n^{0}$ 30/2020 Conselho Estadual de Educação/AM de 18.03.2020, no art. $2^{\circ}$, estabelece:

Estabelecer regime de aula não presencial no âmbito de todo o Sistema de Ensino do estado do Amazonas, definindo essencialmente pela manutenção das atividades pedagógicas sem a presença de alunos ou professores nas dependências escolares, dependendo se efetivar por meio de regime de colaboração entre entes federados e autoridades do sistema de ensino do estado do Amazonas.

Enquanto profissional, tive a identidade docente totalmente superdimensionada, entendendo a identidade docente com a colaboração do conceito de Pimenta (1999), que apresenta a identidade como uma construção histórico-social e ainda, com a contribuição de Lawn (2000), ao discorrer sobre a identidade docente com relação à profissionalização docente.

Ataíde e Nunes (2016, p. 172) as discorrer sobre a identidade da profissão docente acrescentam:

A compreensão da identidade da profissão docente como resultante de um processo histórico de construção social a partir de fatores sociais, culturais, políticos e econômicos, revela-se imperativa para a sua caracterização e diferenciação em relação a outras profissões. [...] Assim sendo, a identidade parte da fusão de elementos caracterizadores dos indivíduos e localizados no tempo e no espaço de forma a torná-los singulares, inconfundíveis no conjunto de seus pensamentos, 
sentimentos e ações, perpassando pelos aspectos subjetivos e objetivos de sua existência.

Assim, acrescento a importância da reflexão dessa identidade, que pertence à mulher professora, mas que sobrepõe à profissão docente, colocando em um patamar muito superior, e deixa a mostra a fragilidade da mulher mãe, quase anulada diante do excesso de demandas para o cumprimento da prática com aula remota. A sala de aula se estendeu a privacidade do lar e me forçou a uma reinvenção de práticas para atender a demanda dos alunos. Não houve por parte das secretarias um acompanhamento sócio-emocional, formação técnicapedagógica, ou o recebimento de incentivo para compra de equipamento tecnológico.

A parceria dos professores no compartilhamento de ideias é um ponto extremamente relevante, pois alguns têm em seu processo didático, práticas com uso mais presente de recursos tecnológicos, e essa troca de experiências veio de encontro ao colaborar na organizar o planejamento diário das aulas. A prática se deu com o uso de recursos próprios e o mínimo de equipamento para organizar os vídeos, adaptação de atividades, materiais de revisão, resumos de aula e planejamento. Existe organização e um planejamento, porém as demandas nesse modelo romperam toda estrutura fundamentada na rotina da prática docente presencial e vão de encontro com a minha própria intimidade, no que toca a privacidade do lar, ao uso de contas pessoais que se tornaram de livre acesso aos pais e alunos, e também a intimidade dos alunos.

O contato com alunos, pais e responsáveis para orientação do acompanhamento das atividades se deu de forma complexa, porque além da professora, as famílias também estão vivendo o período da pandemia. Por mais que a professora se prestasse a orientar e se colocasse a disposição dos alunos, existem outras vertentes escondidas no processo educacional que influenciam diretamente o bom desenvolvimento da atividade, e que estão além da orientação, como a questão da formação básica dos pais, questões econômicas, questões de didática, questões emocionais e de saúde, entre outros. 
O processo de avaliação de forma remota se dá continuamente em que os alunos ou os pais e responsáveis vão encaminhando as atividades diariamente, em formato de registros de vídeos, fotos no processo e concretização das atividades dentro de suas possibilidades. A intenção não é disponibilizar uma nota, mas a professora tem o papel de analisar essas evidências e buscar a partir delas, dar suporte as atividades com maior complexidade, tirar dúvidas, propor atividades para consolidar determinada aprendizagem, buscando colaborar em todo processo, e verificar quem está acompanhando as atividades.

O desafio é imenso porque envolve maior organização para correção, demanda um desgaste grande por conta do tempo e atendimento em jornada fora do horário de trabalho, exige domínio e melhor recurso tecnológico no trato com o armazenamento para o recebimento dos arquivos, porque são trabalhos individuais por turma, e recebidos diariamente. Após esse processo o planejamento se torna mais complexo e necessita de reformulações diárias, porque exige um retorno ao aluno, a atividade precisa estar contextualizada e adaptada ao processo, fazendo link com a aula televisionada, procurando o melhor suporte para facilitar o entendimento do conteúdo dado na aula, e ainda se procura fazer uma atividade diferenciada para atender aos que tiveram dificuldades em determinado conteúdo.

A mulher professora se coloca em evidência diante dessa contextualização porque além dessas tramas ela precisa dar conta do ser mulher, se for mãe, precisa articular o cuidado do filho a demanda do trabalho, e se o filho tiver em idade escolar ainda, deve colaborar no desenvolvimento educacional, além de sua rotina de trabalho, da obrigação assumida com os pais e responsáveis dos seus alunos no acompanhamento das atividades.

A exaustão, o processo de adoecimento emocional, o número de professoras infectadas e a precarização da profissão são invisibilizados nos dados apontados pelas mídias sociais e pelas secretarias, porém os registros de práticas e relatos dos alunos ressalta a importância técnica- pedagógica da mulher professora, sua postura no ensino não presencial reflete a competência no processo de ensinoapredizagem e compromisso, quase sacerdócio com a profissão. Desafios que se 
configuram também no papel da mulher que se coloca no exercício de mestranda e pesquisadora em educação, desafios retrados a seguir.

\section{Desafios da mestranda em um mestrado em Ensino Tecnológico}

As aulas em nível de pós-graduação iniciaram de forma remota, e prosseguimos com o desafio de conciliar o mestrado, a docência, a maternidade, os desafios de ser mulher dentro dessa estrutura totalmente nova, asseguradas pela Portaria $\mathrm{n}^{\mathrm{o}} \cdot 345$, que decide:

Portaria no. 345 , de 19 de março de 2020, no seu artigo $1^{\circ}$ decide: Autorizar, em caráter excepcional, a substituição das disciplinas presenciais, em andamento, por aulas que utilizem meios e tecnologias de informação e comunicação, por instituição de educação superior integrante do sistema federal de ensino, de que trata o art. $2^{\circ}$ do Decreto $n^{0}$ 9.235, de 15 de dezembro de 2017.

As aulas iniciaram com a ajuda da plataforma Google, através do Google Classroom e Google Meet, exigindo uma alta capacidade de resiliência e maior postura do mestrando diante do desafio do exercício da autonomia na pesquisa, no acompanhamento das aulas que iniciavam as oito e seguiam até ao meio dia.

A primeira disciplina trouxe o desafio de discutir os Fundamentos da Formação de Professores para o Ensino Tecnológico, com uma metodologia totalmente nova. Trata-se de usar as narrativas e autobiografias como possibilidade da formação de professores e como técnica de avaliação a construção de um artefato que deixasse registrado o uso da narrativa da própria mestranda no processo de desenvolvimento da disciplina com uso da estratégia de cartas autobiográficas.

Paiva (2008, p.01) considera sobre o significado de narrativa:

Muitos são os significados de narrativa que circulam entre nós: uma história; algo contado ou recontado; um relato de um evento real ou fictício; um relato de uma série de eventos conectados em seqüência; um relato de acontecimentos; uma seqüência de eventos passados; uma série de eventos lógicos e cronológicos, etc. 
Essa disciplina deixou marcas significativas que colaboraram para construção deste relato, pois à medida que me colocava enquanto autora na escrita do processo reflexivo do conhecimento que estava desenvolvendo, eram latentes as dificuldades enfrentadas que aconteciam no meu eu, enquanto mulher, mãe e professora, e influenciavam diretamente a minha prática profissional, o meu processo de aprendizagem e produção de conhecimento.

Durante esse período foram mais de 3000 mortes no Amazonas, perdi uma aluna e vários amigos vítimas da COVID-19, tiveram momentos em que parei tudo que estava produzindo, repirei, chorei, e recomecei a escrever, retratando o humano que pulsa no desafio de ser mulher dentro dessa teia de problematizações que envolvem a construção da própria história de vida, que não se separa da identidade profissional.

Registra-se que os desafios enfrentados por mim, pertenciam também as minhas colegas, cada uma enfrentando ao seu modo o medo, e a necessidade de seguir perseverante na busca pelo conhecimento. Um dos itens de avaliação solicitado foi à produção de um artefato tecnológico que colocasse a disposição o registro todas as produções que a equipe foi construindo diante das leituras, dos debates, e orientações dos professores.

Desta forma, a equipe optou pela escolha do site, pelas várias possibilidades de organização do material, pela possibilidade do trabalho ao mesmo tempo com as várias autoras e suas habilidades individuais que marcam esse período, como uso de música, imagens, cartas, e claro os vários diálogos dentro das redes sociais para construir o trabalho e firmar os vínculos, das mulheres ali presentes, cada uma com suas especificidades e desafios.

Para Silva (2002, p.16), as tecnologias rompem fronteiras:

Imersos em uma nova era, diante de novos rumos, evidenciados pelas atuais tecnologias, rompendo as fronteiras do tempo e do espaço e acenando para imensas possibilidades que se abrem para o futuro da humanidade, o avanço tecnológico impõe novos modos de relação com o saber, com o fazer e com o aprender, com as relações interpessoais e com a cultura, desafiando os educadores preocupados com a educação. 
Participar de um mestrado em Ensino Tecnológico é um dos marcos na minha prática docente e na rápida assimilação de tecnologias para colaborar no desenvolvimento das aulas nesse período. Eu já tinha o domínio de um usuário básico, mas nenhuma habilidade na construção de site, na formulação de questionários, na produção de podcast, produção de vídeo, contanto com programação de jogos, construção de sala de aula virtual, escrita de documentos usando o drive, e esse foi o grande presente que a disciplina Ensino em Tecnologia da Informação e Comunicação trouxe.

Essas práticas me fizeram refletir sobre a formação docente, sobre o desafio que a pandemia coloca ao mundo no enfrentamento da educação e posso afirmar que dentro dos quinze anos de carreira, não tive nenhuma formação contínua ou continuada nesse nível, o que me despertou olhar para necessidade de mudanças na formação dos professores e a necessidade de se colocar em prática as orientações prescritas na Base Nacional Comum Curricular - BNCC.

Ao refletir sobre as questões que emergem ao me debruçar sobre o processo de construção por trás deste relato, pontuo: os desafios da mulher professora dentro da história e as marcas que ainda reproduzem o patriarcalismo, as tramas da mãe, mulher, professora, pesquisadora invisibilizadas por trás das aulas remotas, as possibilidades do uso da tecnologia como colaboradora no desenvolvimento do conhecimento, a necessidade de refletir sobre a formação do professor e buscar caminhos para subsidiar a prática docente.

\section{Considerações Finais}

Reforço à necessidade da discussão sobre a mulher que é mãe, professora e pesquisadora, me colocando como autora/atora do processo de construção vivido ao realizar esse relato, e afirmo ainda perduram as marcas históricas da desvalorização e desprestígio da mulher na educação, e que os desafios relatados no texto, são somente alguns pontos dentro do universo que permeia objeto deste. 
A pandemia coloca em alerta o mundo diante da necessidade de repensar as práticas educacionais como um todo, e considero o projeto Aula em Casa, desenvolvido no Amazonas, de relevância significativa no Brasil, diante do desafio atípico que a COVID-19 impôs ao Amazonas e a todo o mundo, mas que também aponto enquanto professora envolvida neste processo, que muito se precisa ser feito para que os objetivos de aprendizagem, a formação integral e as condições do trabalho docente sejam respeitados.

Os desafios da mulher dentro da pandemia se colocam mais evidentes ao misto complexo que envolve o ser mulher dentro da profissão docente na estrutura que foi imposta no exercício da aula remota e sobrepõe a profissão que é colocada em um patamar superior, e leva a uma reinvenção didática metodológica com uso da tecnologia, a busca por novas práticas e assimilação de processos para atender a necessidade dos alunos.

Por outra via, causa à invisibilidade da mulher por trás da professora, com desafios de ser mãe, de acompanhar a educação dos filhos, com desafio de se dedicar na produção do conhecimento dentro da pesquisa e, ao mesmo tempo, cuidar de si tanto nas atitudes de prevenção no isolamento, no cuidado da saúde mental e emocional. A própria quebra da privacidade, ao ter compartilhado suas contas pessoais para o contato com os alunos, o uso dos recursos próprios para o investimento em equipamentos para o desenvolvimento das aulas, a utilização da própria residência como espaço de trabalho e aumento da carga horária de trabalho, tanto para a dedicação a produção de material complementar e planejamento, quanto no atendimento aos alunos são fatores que apontam a precarização do trabalho docente, e a desvalorização da mulher professora.

Desta forma, o relato procurou contribuir para a necessidade de discussões sobre a mulher, sobre os desafios que ela enfrenta enquanto mãe, professora e pesquisadora. Aponta a necessidade de valorização da identidade docente, uma formação docente que prime pelas histórias de vida desse público, que é o maior dentro da educação, mas que ainda permanece com uma visão patriarcal pela sociedade. E ainda, a necessidade de se firmar na educação o uso da tecnologia como colaboradora do conhecimento, algo que fica claro no período de 
pandemia, e que há tempos está prescrito nas orientações para uma educação que prime pelo desenvolvimento integral do aluno e valorização da profissão docente.

\section{Referências}

BRASIL. CONSELHO NACIONAL DE EDUCAÇÃO. CONSELHO PLENO. Resolução $C N E / C P n^{o}$ 2, de 22 de dezembro de $2017 a\left(^{*}\right)$ Institui e orienta a implantação da Base Nacional Comum Curricular, a ser respeitada obrigatoriamente ao longo das etapas e respectivas modalidades no âmbito da Educação Básica. Disponível em: http://portal.mec.gov.br/index.php?option=com_docman\&view=download\&ali as =79631 -rcpoo2-17-pdf\&category_slug=dezembro-2017-pdf\&Itemid=30192. Acesso: 20/04/2018.

Brasil. Lei no 9.394. Estabelece as diretrizes e bases da educação nacional. Diário Oficial da União 1996; 20 dez. Brasil. Lei no 9.394. Estabelece as diretrizes e bases da educação nacional. Diário Oficial da União 1996; 20 dez.

BRASIL. Ministério da Educação. Fica autorizada, em caráter excepcional, a substituição das disciplinas presenciais, em andamento, por aulas que utilizem meios e tecnologias de informação e comunicação, por instituição de educação superior integrante do sistema federal de ensino, de que trata o art. $2^{0}$ do Decreto $\mathrm{n}^{0}$ 9.235, de 15 de dezembro de 2017. Portaria no. 345, de 19 de março de 2020. Disponível em: https://abmes.org.br/arquivos/legislacoes/Portariamec-345-2020-03-19.pdf Acesso em: 20.06.2020.

DAMETTO, Jarbas; ESQUINSANI, Rosimar Serena Siqueira. Mãe, mulher... professora! Questões de gênero e trabalho docente na agenda educacional contemporânea. Acta Scientiarum, v. 37, n. 2, p. 149- 155, jul.-dec. 2015.

CONSELHO ESTADUAL DE EDUCAÇÃO. Resolução $n^{\circ} 30 / 2020$, de 18 de março de 2020, do Conselho Estadual de Educação (CEE-AM) Regime de aulas não presenciais no Sistema de Ensino do Estado do Amazonas. e atende os termos do Conselho Nacional de Educação (CNE), no Parecer CNE/CEB No 19/2009. Disponível em: http://www.educacao.am.gov.br/wpcontent/uploads/2020/03/Resolucao-30-ano-2020.pdf. Acesso: 20.04.2020.

LAWN, Martin \& GROSVENOR, Ian. This is who we are and this is what we do: teacher identity and national identity in the mid 2oth century english educational discourse. Paper presented at the ISCHE Conference, Sydney, Australia. (2000). Disponível em: https://www.tandfonline.com/doi /pdf/10.1080/14681360100200119? needAccess=true. Acessso : 20.04.2000.

SECRETARIA DE ESTADO DE EDUCAÇÃO E DESPORTO. Diretrizes Pedagógicas para o Regime Especial de Aulas Não Presenciais do Estado do Amazonas. Departamento de Políticas e Programas Educacionais. Manaus, 2020. Disponível em: http://www.educacao.am.gov.br/wp- 
content/uploads/2020/03/DIRETRIZES-PEDAGoGICAS-23.03.pdf. Acesso em 20.04.2020.

SILVA, Geraldo Lúcio. O Aprender ao aprender na educação tecnológica. Dissertação (mestrado) - Universidade Federal de Santa Catarina, Centro Tecnológico. Programa de Pós-Graduação em Engenharia de Produção, 2002. Disponível em: http://repositorio.ufsc.br/xmlui/handle/123456789/83735. Acesso em 20.06.2020.

PAIVA, Vera Lúcia Menezes de Oliveira. A pesquisa narrativa: uma introdução. Revista brasileira de linguística aplicada. v. 8, n. 2, p. 261-266, 2008. Disponível em: https://www.scielo.br/pdf/rbla/v8n2/en 01.pdf. Acesso em: 20.06.2020.

PIMENTA, Selma Garrido. Formação de professores: identidade e saberes da docência. In: PIMENTA, Selma Garrido. (Org). Saberes pedagógicos e atividade docente. São Paulo: Cortez Editora, 1999. 